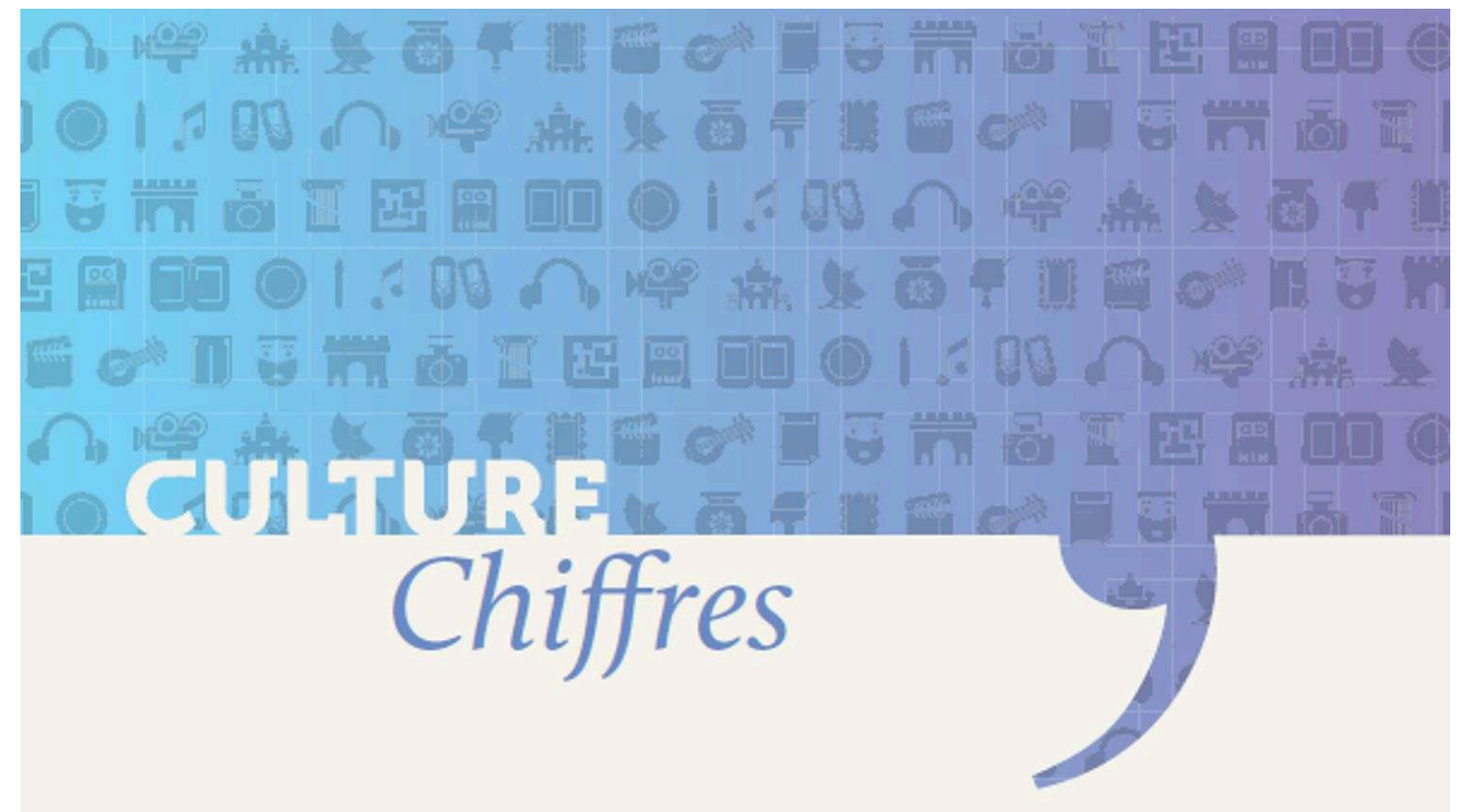

Le poids économique direct de la culture

en 2013

Yves Jauneau

Xavier Niel

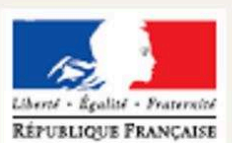

RÉTUBLIOUE FRANCAISE

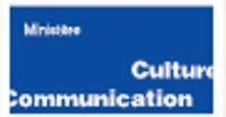

2014-5

Ministère de la Culture et de la Communication

Département des études, de la prospective et des statistiques 


\section{Le poids économique direct de la culture en 2013}

The Direct Economic Impact of Culture in 2013

\section{Xavier Niel et Yves Jauneau}

Éditeur : Département des études, de la prospective et des statistiques

Lieu d'édition : Paris

Année d'édition : 2014

Date de mise en ligne : 21 septembre 2015

Collection : Culture chiffres

ISBN électronique : 9782111398191

\section{Qboooks}

http://books.openedition.org

\section{Édition imprimée}

Date de publication : 1 octobre 2014

Nombre de pages : 20

\section{Référence électronique}

NIEL, Xavier ; JAUNEAU, Yves. Le poids économique direct de la culture en 2013. Nouvelle édition [en ligne]. Paris : Département des études, de la prospective et des statistiques, 2014 (généré le 25 avril 2021). Disponible sur Internet : <http://books.openedition.org/deps/463>. ISBN : 9782111398191.

(C) Département des études, de la prospective et des statistiques, 2014

Creative Commons - Attribution - Pas d'Utilisation Commerciale 3.0 non transposé - CC BY-NC 3.0 


\title{
Le poids économique direct de la culture en 2013
}

\author{
Yves Jauneau, Xavier Niel ${ }^{\star}$
}

En 2013, le poids économique direct de la culture, c'est-à-dire la valeur ajoutée de l'ensemble des branches culturelles est de 44 milliards d'euros. Il ne prend pas en compte les retombées économiques indirectes ou induites par la culture comme le tourisme, par exemple.

Cela correspond à une part de la culture dans l'ensemble de l'économie de $2,3 \%$, en légère baisse par rapport à 2012.

Contribue à cette baisse relative en 2013 le recul du volume de l'activité dans les branches fortement exposées à la concurrence (architecture, agences de publicité, audiovisuel) ainsi que dans les branches de la presse et du livre. Inversement, la part des branches à forte composante non marchande augmente (spectacle vivant, patrimoine), surtout du fait de la hausse de leurs prix.

Parmi les branches les plus touchées par la crise en 2013, les branches de l'audiovisuel et les agences de publicité connaissent un retour à la croissance de leur chiffre d'affaires début 2014, contrairement à celles de l'architecture ou des activités photographiques. Par ailleurs, le retournement à la hausse des prix à la production des entreprises d'édition de livres et de revues se confirme.

* Département des études, de la prospective et des statistiques. 


\section{Une valeur ajoutée culturelle de 44 milliards d'euros en 2013}

En 2013, le poids économique direct de la culture, c'est-à-dire la valeur ajoutée de l'ensemble des branches culturelles (Annexe), peut être estimé à 44 milliards d'euros ${ }^{1}$. Cela correspond à une part de la culture dans l'ensemble de l'économie de 2,3\% (graphique 1 et tableau 1).

Depuis 1995, l'évolution de la part de la culture dans l'ensemble de l'économie est fortement influencée par celle des différentes branches de l'audiovisuel. Par ailleurs, la part de la presse et, dans une moindre mesure, celle du livre baissent continûment, tandis que celles du spectacle vivant et du patrimoine, branches principalement non marchandes, augmentent. Au total, la part de la culture dans l'économie a augmenté jusqu'en 2003, chuté jusqu'en 2008 puis est restée globalement stable jusqu'en 2012.

En 2013, la part de la culture dans l'économie baisse légèrement. Contribuent à cette baisse les branches de l'audiovisuel (et en particulier celles de la musique et du cinéma), de la publicité et de l'architecture, plus sensibles à la conjoncture que les autres branches culturelles, ainsi que les branches du livre et de la presse. Inversement, la part du spectacle vivant, du patrimoine et des arts visuels a augmenté en 2013 (graphique 1).

\section{Graphique 1 - Part des différentes branches culturelles dans la valeur ajoutée de l'ensemble de l'économie, 1995-2013}

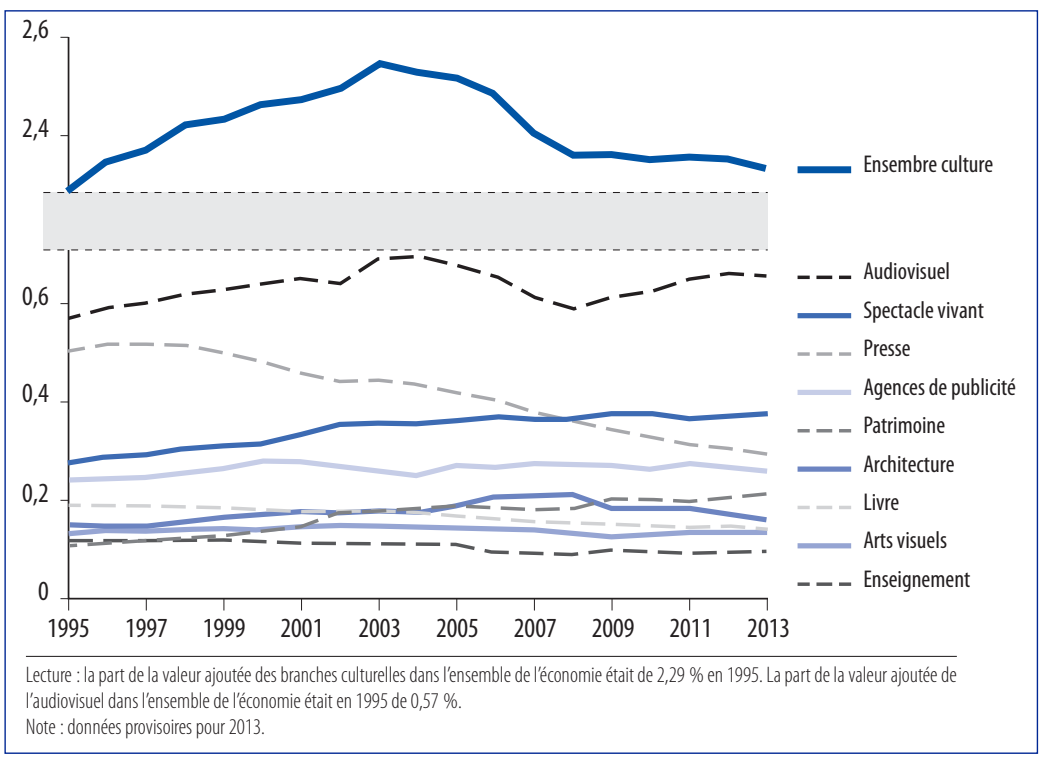

Source : Insee, comptes nationaux - base 2010/DEPS, Ministère de la Culture et de la Communication, 2014

1. Les données présentées dans cette étude sont issues d'une méthode d'estimation mise au point en 2013 par le DEPS (Jauneau, 2013). Les données précédemment publiées ont été toutefois révisées : le périmètre du champ statistique de la culture a été très légèrement modifié (Annexe) ; de plus, les concepts de la comptabilité nationale sur lesquels s'appuie cette méthode ont été révisés en mai 2014 par l'Insee (changement de base) et les données rétrospectives modifiées en conséquence. Les résultats présentés ici annulent donc et remplacent les données publiées jusqu'à présent. Les tendances mises en évidence, notamment en termes d'évolution du poids économique de la culture, ne sont toutefois que très peu affectées par cette révision. 
Tableau 1 - Poids (en valeur ajoutée) et part relative des branches culturelles dans le champ de la culture et dans l'ensemble de l'économie, 1995-2013

\begin{tabular}{|c|c|c|c|c|c|c|c|c|c|}
\hline & $\begin{array}{r}\text { Val } \\
\text { (en milli }\end{array}$ & $\begin{array}{l}\text { eur ajol } \\
\text { ards } d^{\prime} €\end{array}$ & tée & $\begin{array}{r}\text { Part d } \\
\text { de }\end{array}$ & $\begin{array}{l}\text { ns l'en } \\
\text { 'écono } \\
\text { (en \%) }\end{array}$ & $\begin{array}{l}\text { nie } \\
\text { niele }\end{array}$ & $\mid \begin{array}{r}\text { Part d } \\
\text { des bran }\end{array}$ & $\begin{array}{l}\text { ns l'ens } \\
\text { ches cu } \\
\text { (en \%) }\end{array}$ & $\begin{array}{l}\text { emble } \\
\text { turelles }\end{array}$ \\
\hline & 1995 & 2012 & 2013 & 1995 & 2012 & $2013 p$ & 1995 & 2012 & $2013 p$ \\
\hline Audiovisuel & 6,3 & 12,4 & 12,5 & 0,57 & 0,66 & 0,66 & 25,0 & 28,1 & 28,1 \\
\hline Spectacle vivant & 3,0 & 6,9 & 7,1 & 0,28 & 0,37 & 0,38 & 12,0 & 15,7 & 16,1 \\
\hline Presse & 5,5 & 5,7 & 5,6 & 0,50 & 0,31 & 0,29 & 22,1 & 13,0 & 12,6 \\
\hline Agences de publicité & 2,6 & 5,0 & 4,9 & 0,24 & 0,27 & 0,26 & 10,6 & 11,3 & 11,2 \\
\hline Patrimoine & 1,2 & 3,8 & 4,0 & 0,11 & 0,20 & 0,21 & 4,7 & 8,7 & 9,1 \\
\hline Architecture & 1,6 & 3,2 & 3,1 & 0,15 & 0,17 & 0,16 & 6,4 & 7,4 & 6,9 \\
\hline Livre & 2,1 & 2,8 & 2,7 & 0,19 & 0,15 & 0,14 & 8,3 & 6,3 & 6,1 \\
\hline Arts visuels & 1,4 & 2,5 & 2,6 & 0,13 & 0,13 & 0,14 & 5,7 & 5,7 & 5,8 \\
\hline Enseignement & 1,3 & 1,8 & 1,8 & 0,12 & 0,09 & 0,10 & 5,2 & 4,0 & 4,1 \\
\hline Ensemble culture & 25,1 & 44,2 & 44,3 & 2,29 & 2,35 & 2,34 & 100,0 & 100,0 & 100,0 \\
\hline Ensemble de l'économie & 1097,4 & 1878,4 & 1896,9 & 100,0 & 100,0 & 100,0 & & & \\
\hline$p:$ données provisoires pour 2013 & & & & & & & & & \\
\hline
\end{tabular}

Source : Insee, comptes nationaux - base 2010/DEPS, Ministère de la Culture et de la Communication, 2014

\section{Audiovisuel : 2013, année des retournements}

L'évolution du poids de chacune des branches a elle-même deux composantes: l'évolution en volume (c'est-à-dire l'évolution de l'activité à prix constants) et l'évolution des prix (tableau 2).

L'audiovisuel constitue la principale branche d'activité culturelle, avec $28 \%$ de sa valeur ajoutée (tableau 1). Après quatre années de hausse, son poids a quasiment cessé d'augmenter en 2013 (tableau 2). Il est difficile de séparer nettement les différents segments de l'audiovisuel (radio, télévision, cinéma, vidéo ou disque) à partir des nomenclatures d'activités (Annexe) : la postproduction s'applique à la fois au cinéma, à la vidéo et à la télévision; la production de films publicitaires concerne les spots

Tableau 2 - Taux de croissance de la valeur ajoutée entre 2012 et 2013

\begin{tabular}{|lccc|}
\hline & En valeur & En volume & En prix \\
Audiovisuel & 0,3 & $-1,7$ & 2,1 \\
Spectacle vivant & 3,1 & $-1,9$ & 5,1 \\
Presse & $-2,8$ & $-6,7$ & 4,2 \\
Agences de publicité & $-1,0$ & 0,2 & $-1,3$ \\
Patrimoine & 4,8 & 0,0 & 4,9 \\
Architecture & $-5,6$ & $-5,0$ & $-0,6$ \\
Livre & $-2,8$ & $-4,2$ & 1,5 \\
Arts visuels & 2,9 & 3,4 & $-0,5$ \\
Enseignement & 4,1 & 3,1 & 1,0 \\
\hline Ensemble culture & 0,2 & $-1,9$ & 2,2 \\
\hline Ensemble de l'économie & 1,0 & 0,3 & 0,7 \\
\hline Note : données provisoires. & & & \\
\hline
\end{tabular}


quels que soient leurs supports de diffusion (télévision, cinéma); les vidéos ne présentent plus seulement des longs métrages, mais aussi, et de plus en plus, des séries télévisées ; les points de vente de disques distribuent aussi des vidéos, etc. On peut toutefois affirmer que les activités globalement liées à la vidéo et au cinéma subissent une baisse en 2013 (notamment la distribution de films et leur projection en salles) tandis que celles liées à la télévision continuent de progresser, pour les chaînes généralistes et plus particulièrement encore pour les chaînes thématiques.

Le retournement dans les activités cinématographiques est dû à un repli en volume. Selon le CNC, c'est la première fois depuis 2009 que les entrées en salles ne franchissent pas la barre des 200 millions. Elles avaient culminé en 2011 grâce au succès d'Intouchables. L'année 2013 a été marquée par l'absence de très grands succès et ce, quelle que soit la nationalité des films. Pour la première fois depuis plus de dix ans, aucun film ne réalise plus de 5 millions d'entrées alors qu'on en comptait trois en 2012. Les prix dans le secteur du cinéma sont en revanche à la hausse, en particulier pour le prix des places dans les salles de cinéma (projection de films). Cette hausse des prix prolonge une tendance amorcée depuis plus de dix ans, et n'est donc pas de nature à relancer l'activité en volume.

La croissance des activités d'édition musicale et celle de l'édition de vidéo ont toutes deux été stoppées au début des années 2000 (graphique 2). L'édition de vidéo a ensuite stagné, tandis que l'édition musicale s'est effondrée. Ce dernier secteur semble toutefois être parvenu à s'organiser de façon à surmonter ses difficultés puisque l'activité d'édition musicale et d'enregistrement sonore poursuit, en 2013, le redressement observé en 2012. Cette tendance s'explique par un retournement de la demande des ménages: d'après le Syndicat national de l'édition phonographique (SNEP), 2013 a été une année atypique. La hausse concerne à la fois les ventes physiques (+ $1 \%)$, une première depuis 2002 , et les ventes numériques (+ $0,6 \%)$. La croissance est tirée à la fois par les ventes d'albums et par les revenus de la diffusion numérique (téléchargement, et diffusion en flux ou streaming). Le développement récent du téléchargement de musique sur des plates-formes légales semble relancer l'activité d'édition musicale: en 2013, $26 \%$ du chiffre d'affaires des ventes de phonogrammes provient des ventes numériques, contre seulement $3 \%$ en 2005.

En revanche, la situation du commerce de détail en magasin spécialisé est tout autre puisque sa valeur ajoutée a plongé sans discontinuer depuis 2009 (graphique 2).

\section{Graphique 2 - Valeur ajoutée des branches d'édition et de commercialisation de musique et de vidéo, 1995-2013}

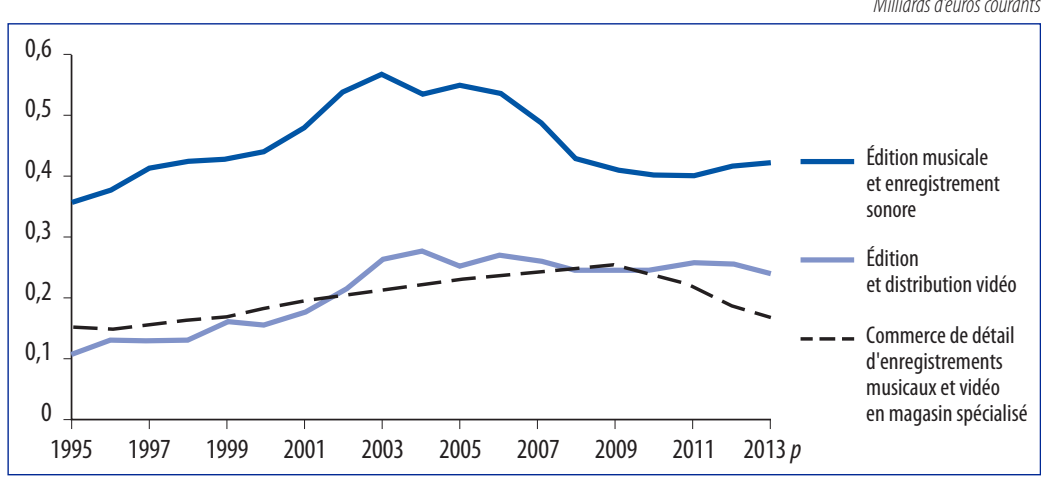

Source : Insee, comptes nationaux - base 2010/DEPS, Ministère de la Culture et de la Communication, 2014 
En quelque sorte, l'internet contribue encore à dégrader les marges d'une certaine forme de distribution physique de la musique, tandis que l'activité dans l'édition musicale s'est stabilisée depuis quatre ans.

\section{Livre et presse : baisse continue depuis quinze ans}

En 1995, le livre et la presse constituaient la première activité économique culturelle, concentrant $30 \%$ de valeur ajoutée culturelle. Plus de quinze ans plus tard, ces deux activités ne concentrent plus que $19 \%$ de la valeur ajoutée culturelle. Ce recul, nettement plus marqué pour la presse que pour le livre, semble directement lié à celui de la pratique de la lecture des Français, observé par les enquêtes du ministère de la Culture sur les pratiques culturelles des Français. La part relative de ces secteurs dans l'ensemble de l'économie ne cesse de perdre du terrain (graphique 3).

Pour la presse, le recul du lectorat s'est accompagné de l'arrivée massive des gratuits au début des années 2000, entraînant le recul des investissements publicitaires dans la presse payante et donc l'affaiblissement de sa capacité de financement. La baisse du nombre des lecteurs de journaux et revues et celle des financements du secteur n'ont toutefois pas affecté le nombre de titres de presse et une certaine variété de l'offre semble donc maintenue : selon les enquêtes du ministère menées auprès des services de presse, il y avait en 2012 près de 4700 titres de presse papier, soit plus de 1500 de plus qu'en 1995, alors même que la diffusion totale annuelle est passée de 7 milliards d'exemplaires en 1995 à 5 milliards en 2012.

L'évolution des prix à la production des entreprises d'édition s'est inversée en 2013 : dans l'édition de journaux, la hausse des prix observée depuis fin 2011 a cessé. Dans l'édition de revues et de livres, la baisse récente des prix à la production s'est trouvée enrayée (graphique 4).

\section{Graphique 3 - Activités liées à l'imprimé : part de la valeur ajoutée dans l'ensemble de l'économie, 1995-2013}

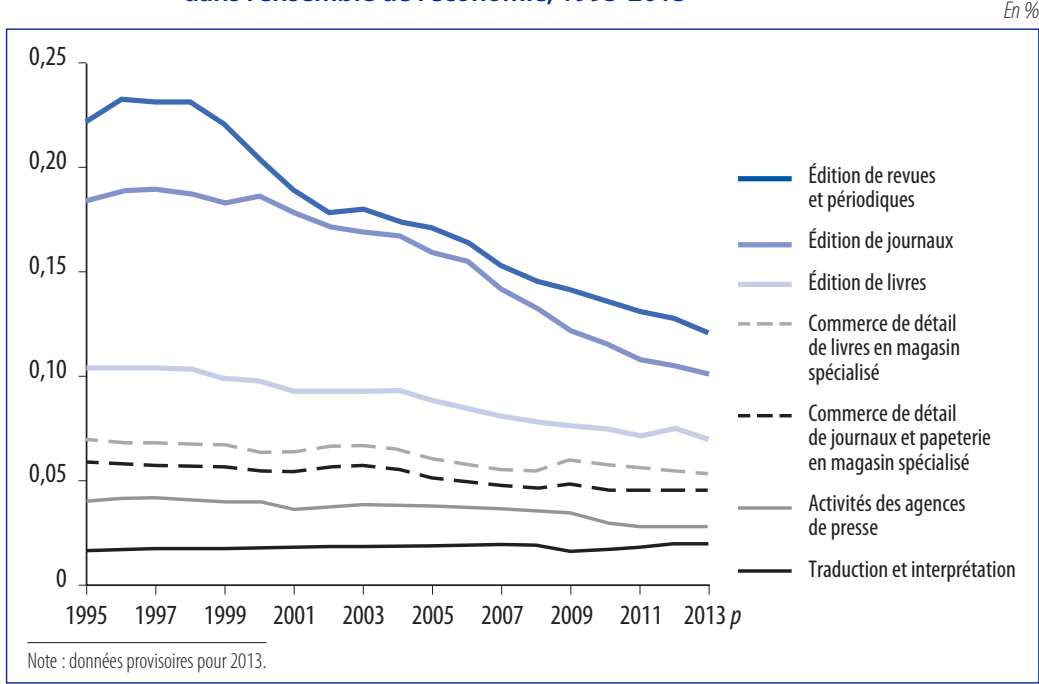

Source: Insee, comptes nationaux - base 2010/DEPS, Ministère de la Culture et de la Communication, 2014 
Graphique 4 - Évolution des prix à la production dans les secteurs de l'édition, 2012-2014

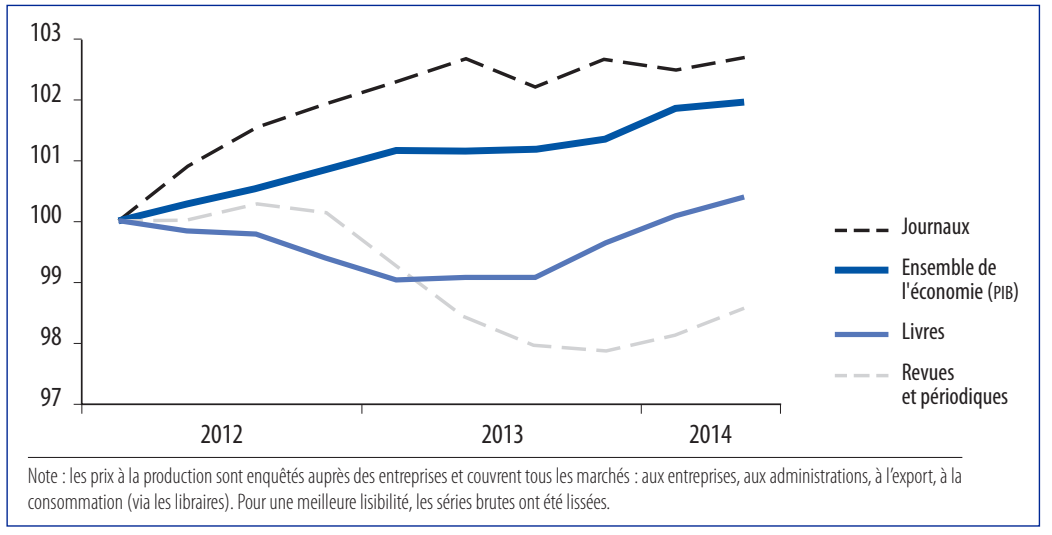

Source : Insee, indices de prix de production des services; comptes nationaux - base 2010/ DEPS, Ministère de la Culture et de la Communication, 2014

\section{La part du spectacle vivant progresse grâce à l'augmentation des prix}

Selon les comptes nationaux, un ménage français consacre en 2013 environ $20 \%$ de ses dépenses culturelles aux sorties (spectacles, musées, monuments historiques, etc.), contre $8 \%$ en 1995. La part du spectacle vivant et celle du patrimoine dans l'économie ont de fait régulièrement progressé depuis une quinzaine d'années (tableau 1).

Estimée selon les concepts des comptes nationaux, la progression de la part du spectacle vivant dans l'ensemble de l'économie provient surtout de l'augmentation de ses prix (tableau 2). Constatant un chiffre d'affaires en moindre augmentation que les prix, l'Insee en déduit une baisse du volume de l'activité dans le secteur marchand (graphique 5).

Graphique 5 - Évolution du chiffre d'affaires et des prix dans le spectacle vivant (secteur marchand), 2010-2014

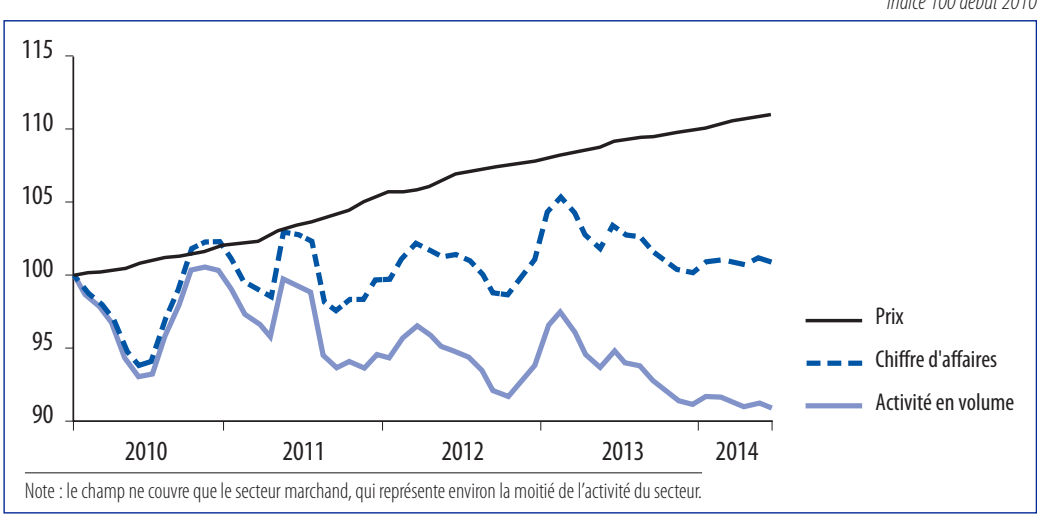

Source: Insee, indices de chiffres d'affaires, déclaration de TVA (CA3), indices de prix à la consommation/ DEPS, Ministère de la Culture et de la Communication, 2014 
Pourtant, d'après les données collectées par le Centre national de la chanson, des variétés et du jazz (cNv), le nombre d'entrées pour les spectacles de musique a augmenté plus vite que le prix moyen d'une entrée. D'après l'Association pour le soutien du théâtre privé (ASTP), le prix moyen des entrées au théâtre n'a pas augmenté depuis 2009 (graphique 6). Ces résultats sont donc apparemment contradictoires avec les données de l'Insee qui retracent une hausse des prix et une baisse du volume de l'activité.

Cela peut s'expliquer par le fait que le public des spectacles s'oriente de plus en plus vers des places moins chères ou vers des spectacles moins coûteux ; cela peut aussi refléter les pratiques promotionnelles visant à encourager les achats de dernière minute, promotions facilitées par l'internet et non prises en compte dans les indices de prix de l'Insee (encadré 1).

\section{Encadré 1}

\section{Pour comprendre l'indice des prix}

L'indice des prix utilisé dans les comptes nationaux mesure l'évolution des prix d'un panier de services précisément identifiés: par exemple la place de $1^{\text {re }}$ catégorie d'une salle de théâtre, la place de $5^{\mathrm{e}}$ catégorie de cette même salle, l'entrée pour une journée à un festival de musique rock en province, le prix d'une place d'orchestre pour un spectacle d'opéra, etc. Chaque mois, les prix sont mesurés lors de la transaction, c'est-à-dire au moment où le billet est acheté, en général bien avant la date de la représentation. Si d'une année à l'autre le prix de ces places n'évolue pas, l'indice des prix reste stable.

Supposons que pendant le même temps le nombre d'entrées reste stable aussi, mais que les spectateurs délaissent les places chères (1 ${ }^{\text {re }}$ catégorie) pour acheter des places moins onéreuses (de $5^{e}$ catégorie), ou qu'ils délaissent les spectacles coûteux (l'opéra) pour préférer des spectacles meilleur marché (concerts dans des petites salles), la recette sera moindre, car le nombre d'entrées est le même, mais le prix moyen d'une entrée a baissé. De même, si la composition du public change, et que les nouveaux spectateurs, par exemple plus jeunes, préfèrent les spectacles de musique actuelle, tandis que ceux qui n'y vont plus, plus âgés, allaient à l'opéra, plus cher, la recette globale des spectacles (tous genres confondus) sera moindre, toujours à nombre d'entrées identique.

L'effet qui résulte de ce changement de comportement est enregistré par l'Insee non pas dans l'indice des prix mais dans l'activité en volume, c'est l'« effet qualité ». La comptabilité nationale considère en effet que le service consommé n'est pas le même et que c'est le PIB (donc la richesse en volume) qui doit intégrer cette différence et non pas l'indice des prix, puisque les prix des places de chacune des catégories, eux, n'ont pas évolué.

Par ailleurs, l'indice des prix de l'Insee n'intègre pas les promotions de dernière minute, concédées par exemple lorsque la salle n'est pas suffisamment remplie. Les prix sont mesurés assez en amont de la date de la représentation pour pouvoir mesurer un nombre suffisant de transactions; ils entrent en revanche dans le calcul de l'indice des prix du mois de la représentation du spectacle. Trop près de la date de la représentation, on risquerait de ne plus avoir de transactions à observer. Lorsque ces prix sont mesurés, ce sont donc très souvent les tarifs qui sont collectés. Lors d'une promotion, la nature du service n'a pas changé (catégorie d'une place, type de spectacle) et cela devrait donc en toute logique être intégré dans l'évolution des prix, mais la contrainte technique oblige I'Insee à ne pas prendre en compte ces pratiques, qui se retrouvent du coup retracées dans l'évolution du volume, calculée en rapportant l'évolution du chiffre d'affaires (en valeur) à celle de l'indice des prix.

Au total, la baisse de l'activité en volume retracée dans les comptes nationaux reflète donc à la fois l'évolution du nombre d'entrées, les modifications de comportements des publics et les pratiques de promotion de dernière minute, sans pouvoir les séparer. 


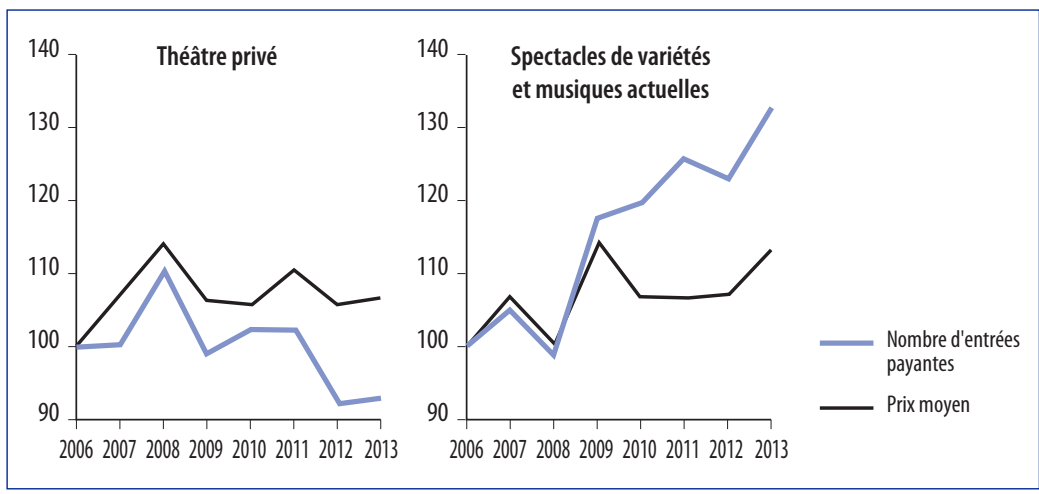

Sources: Centre national de la chanson, des variétés et du jazz (CNV), Association pour le soutien du théâtre privé (ASTP)/ DEPS, Ministère de la Culture et de la Communication, 2014

\section{Hausse de la part du patrimoine}

La progression des activités liées au patrimoine est portée depuis dix ans par une forte hausse de la fréquentation dans les musées: 62 millions de visiteurs ont été accueillis dans les musées labellisés musées de France en 2012, contre 45 millions en 2004 , soit une hausse annuelle moyenne de $4 \%$. Si la progression du nombre d'entrées s'explique en partie par l'évolution de la proportion d'entrées gratuites (31 \% en 2004, $43 \%$ en 2012), on doit aussi ce dynamisme à l'attractivité touristique du territoire, car la hausse est d'abord le fait des visiteurs étrangers. Ainsi, dans les quatre premiers musées français en termes de visiteurs, qui concentrent plus de $40 \%$ de la fréquentation des musées de France (Louvre, Château de Versailles, Centre Pompidou, Orsay), deux visiteurs sur trois sont étrangers.

\section{Stabilité de la part de l'enseignement artistique}

L'enseignement artistique représente $0,1 \%$ de l'ensemble de l'économie et $4 \%$ de la valeur ajoutée culturelle, et reste relativement stable sur une longue période (tableau 1). Couvrant aussi bien les écoles privées que les conservatoires et les écoles supérieures artistiques et culturelles relevant du ministère de la Culture et de la Communication, $86 \%$ de son activité est non marchande (Annexe) et réagit de ce fait assez peu aux fluctuations conjoncturelles de l'économie.

\section{L'architecture et les agences de publicité, activités culturelles les plus touchées par la crise en 2008-2009 comme en 2013}

Trois activités culturelles (architecture, agences de publicité, services photographiques) ont un fonctionnement qui les rapproche davantage des secteurs non cultu- 
rels : leur activité est moins corrélée à la dépense publique et le profil des actifs qu'elles emploient se rapproche de la moyenne de l'ensemble de l'économie. À ce titre, les services d'architecture ont été davantage touchés que les autres activités culturelles par la crise économique de 2008-2009. Ainsi, la réduction du nombre de mises en chantier de logements et de bâtiments non résidentiels a entraîné, en 2008, un recul significatif des projets architecturaux. À l'époque, ce repli n'a pas été compensé par les prix, et le chiffre d'affaires a immédiatement chuté. Les prix ont alors cessé d'augmenter (graphique 7). S'en est suivie une certaine reprise de l'activité, mais à partir de 2012 l'activité en volume a de nouveau chuté, entraînant cette fois-ci avec elle les prix à la baisse, signe d'une grave crise dans ce secteur.

Les agences de publicité sont considérées, dans tous les groupes de travail internationaux ayant travaillé sur les nomenclatures culturelles, comme ayant une activité créative et classées, à ce titre, parmi les activités culturelles. Les recettes des régies publicitaires n'en font en revanche pas partie. Les agences de publicité regroupent $11 \%$ de la valeur ajoutée culturelle en 2013, devant donc le patrimoine, les activités d'architecture, les arts visuels (arts plastiques, design, photographie) et l'enseignement culturel (tableau 1). Les activités des agences de publicité n'ont pas réagi comme l'architecture à la crise de 2008-2009: leurs prix ont immédiatement et fortement baissé, permettant ainsi le maintien de la croissance du volume d'activité et un certain maintien du chiffre d'affaires. Lors du ralentissement de 2012 en revanche, les prix

Graphique 7 - Évolution du chiffre d'affaires et des prix, 2006-2014

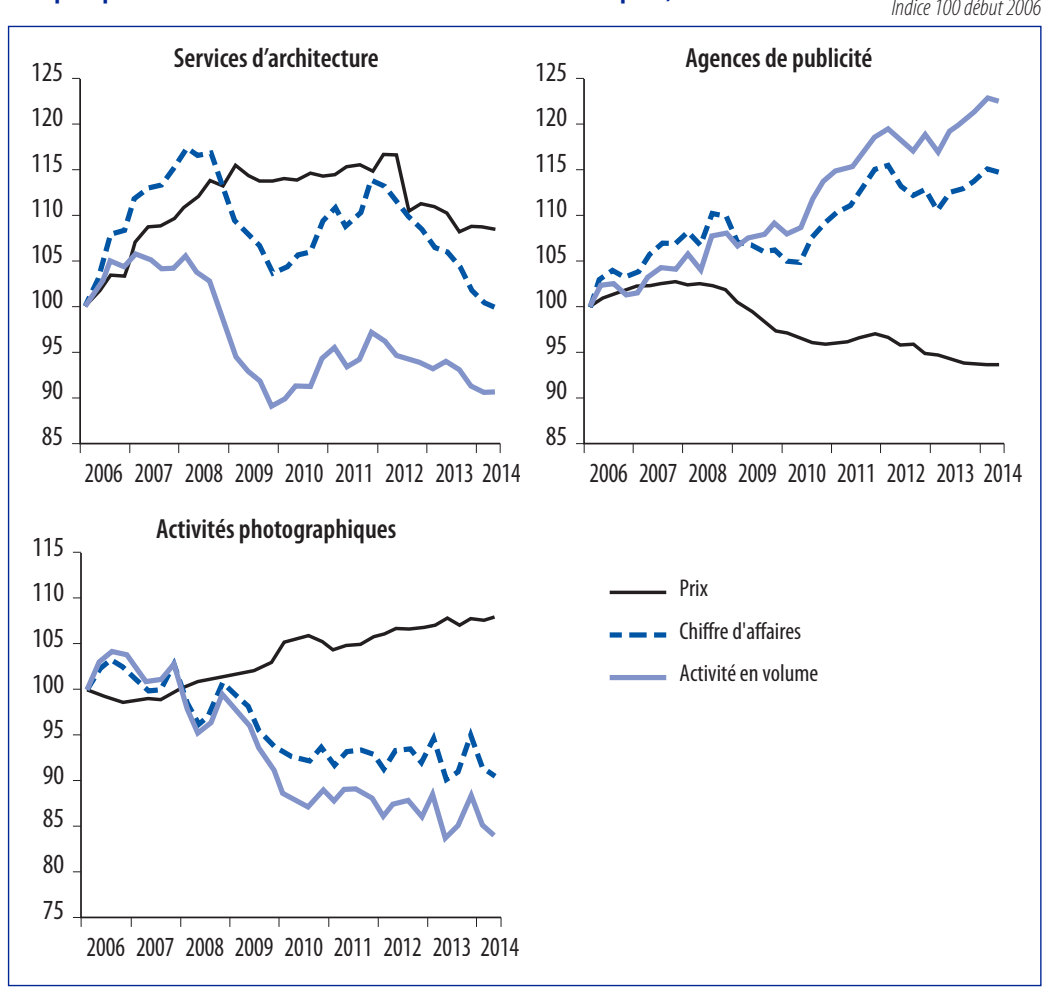

Sources: Insee, indices de chiffres d'affaires, déclaration de TVA (CA3) ; indices de prix de production des services. Les indices de prix des agences publicitaires ont été lissés pour une meilleure lisibilité/DEPS, Ministère de la Culture et de la Communication, 2014 
n'ont pas pu s'ajuster à la baisse avec la même ampleur qu'en 2009, et le volume d'activité a stagné. Début 2014 marque cependant une nette reprise (graphique 7).

Les activités photographiques sont affectées par une crise plus structurelle, du fait du développement des technologies numériques depuis plusieurs années. Les prix n'ont cependant pas baissé, et l'activité se réduit de façon continue jusqu'en 2011 ; elle stagne depuis, tandis que le chiffre d'affaires du secteur progresse très faiblement (graphique 7).

Au total, la valeur ajoutée des branches culturelles n'augmente pas en 2013 autant que le reste de l'économie. Cela tient surtout au recul du volume d'activité dans les secteurs fortement exposés à la concurrence (presse, architecture, audiovisuel). En compensation, dans les branches à forte composante non marchande comme le spectacle vivant et le patrimoine, les prix en forte augmentation tirent à la hausse le poids de la valeur ajoutée des branches culturelles.

\section{Annexe}

\section{Comment mesurer le poids de la culture dans l'économie?}

Mesurer le poids de la culture dans l'économie nécessite, d'une part, de définir le contour statistique de la culture et, d'autre part, de réussir à résumer en un seul indicateur macroéconomique l'activité d'acteurs culturels pour le moins divers : des grandes entreprises de l'audiovisuel aux petites associations culturelles locales, ou encore des théâtres subventionnés aux architectes non salariés.

La définition du champ de la culture est à elle seule une question à part entière, à laquelle les réponses apportées n'ont cessé de diverger dans le temps ou selon les pays. Au-delà d'activités que tout le monde considérera comme indiscutablement culturelles (spectacle, lecture de livres, cinéma, etc.), doit-on prendre en compte toutes celles qui interviennent à un moment donné dans la chaîne de production des biens et services culturels (imprimerie pour un livre par exemple), ou encore toutes celles qui comportent un aspect artistique ou créatif (la gastronomie, la confection de chaussures) ? Ou, pour aller plus loin encore, toutes celles dont une partie du chiffre d'affaires n'existerait peutêtre pas sans la culture (tourisme, BTP) ?

Se fonder sur une définition très extensive de la culture pose différents problèmes: elle implique des doubles comptes entre les différentes branches d'activité, ce qui rend inopérantes les comparaisons entre secteurs (les restaurants peuvent par exemple apparaître à la fois dans le tourisme et dans la culture), et elle nécessite des choix méthodologiques délicats, voire impossibles : quelle est la part culturelle dans la gastronomie ou la confection de chaussures?

Une fois le champ défini, la valeur ajoutée de la culture est calculée à l'aide des données et selon les concepts de la comptabilité nationale qui servent à l'Insee à établir le PIB (Jauneau, 2013). Une des particularités de l'activité économique culturelle est la place non négligeable qu'y occupe le « non-marchand ». Rapporter le poids de la culture à celui de l'économie doit intégrer cette particularité.

\section{1 - Le champ statistique de la culture défini de manière harmonisée au niveau européen}

Les données présentées dans cet article se fondent sur une définition harmonisée de la culture, décidée de façon conjointe par les différents services statistiques européens de la culture en 2009, sous l'égide d'Eurostat, l'Office statistique de l'Union européenne (Deroin, 2011). Le champ de la culture est ici défini en référence à la nomenclature d'acti- 
vités française (NAF), par la sélection de 34 codes parmi les 732 qui composent la nomenclature à son niveau le plus désagrégé (voir tableau Activités culturelles). C'est un contour relativement large, qui englobe l'ensemble du périmètre de compétences du ministère de la Culture et de la Communication en France, ainsi que les agences de publicité, prises en compte dans le champ statistique de la culture pour leur aspect créatif ; les activités des régies publicitaires ne sont en revanche pas prises en compte, car non créatives. Le groupe de travail d'Eurostat a suivi en cela les pratiques de la plupart des autres travaux internationaux du même type.

N'ont en revanche pas été retenues par Eurostat les activités industrielles qui ne permettent que la reproduction de produits culturels mais qui n'y apportent pas de valeur qu'on aurait pu considérer comme culturelle: l'imprimerie, les équipements et matériaux (depuis la fabrication des optiques jusqu'à celle des peintures ou autres encres et vernis d'imprimerie) et, pour les mêmes raisons, la reproduction et la fabrication d'instruments de musique.

Le champ harmonisé au niveau européen retenu ici correspond donc au poids direct des branches culturelles, à l'exclusion des activités indirectement culturelles (l'imprimerie par exemple) et des activités induites par ces branches (la part du BTP dédiée à la rénovation du patrimoine par exemple).

\section{Activités culturelles}

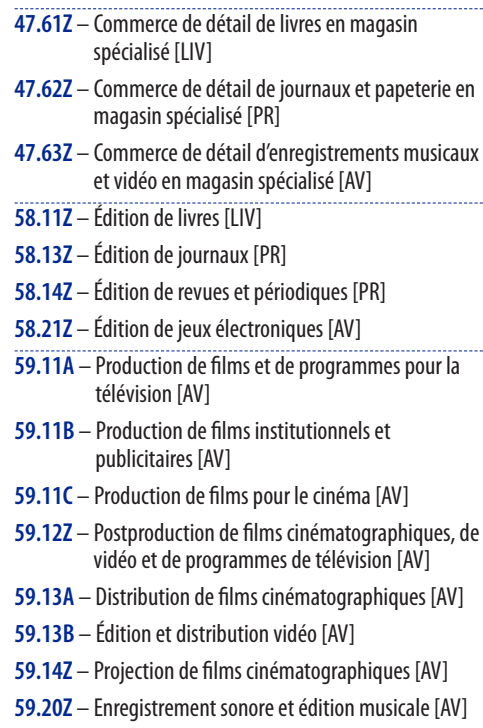

47.62Z - Commerce de détail de journaux et papeterie en magasin spécialisé [PR]

47.63Z - Commerce de détail d'enregistrements musicaux et vidéo en magasin spécialisé [AV]

58.11Z - Édition de livres [LiV]

58.13Z - Édition de journaux [PR]

$58.14 Z$ - Édition de revues et périodiques [PR]

58.21Z - Édition de jeux électroniques [AV]

$59.11 \mathrm{~A}$ - Production de films et de programmes pour la télévision [AV]

59.11B - Production de films institutionnels et publicitaires [AV]

59.11C - Production de films pour le cinéma [AV]

$59.12 Z$ - Postproduction de films cinématographiques, de vidéo et de programmes de télévision [AV]

59.13A - Distribution de films cinématographiques [AV]

59.13B - Édition et distribution vidéo [AV]

$59.14 Z$ - Projection de films cinématographiques [AV]

59.20Z - Enregistrement sonore et édition musicale [AV]

$60.10 Z$ - Edition et diffusion de programmes radio [AV]

$60.20 \mathrm{~A}$ - Édition de chaînes généralistes [AV]

60.20B - Édition de chaînes thématiques [AV]

63.91Z - Activités des agences de presse [PR]

71.112 - Activités d'architecture [ARCHI]

73.11Z - Activités des agences de publicité [PUB]

74.10Z - Activités spécialisées de design [ART]

$74.20 Z$ - Activités photographiques [ART]

74.302 - Traduction et interprétation [LIV]

77.22Z - Location de vidéocassettes et disques vidéo [AV]

85.52Z - Enseignement culturel [*] [EC]

90.01Z - Arts du spectacle vivant [SV]

90.02Z - Activités de soutien au spectacle vivant [SV]

$90.03 \mathrm{~A}$ - Création artistique relevant des arts plastiques [ART]

90.03B - Autre création artistique [ART]

90.04Z - Gestion de salles de spectacles [SV]

91.01Z - Gestion des bibliothèques et des archives [PAT]

91.02Z - Gestion des musées [PAT]

91.03Z - Gestion des sites et monuments historiques et des attractions touristiques similaires [PAT]

(*) Le code $8552 Z$ exclut les établissements d'enseignement supérieur (dont ceux relevant de la Culture), qui sont classés en code $8542 Z$ (Enseignement supérieur). Ces établissements (une centaine environ) sont ici pris en compte dans l'estimation de la valeur ajoutée.

Note : les activités culturelles sont regroupées en neuf domaines : AV : audiovisuel; SV : spectacle vivant; PAT : patrimoine ; EC : enseignement culturel ; LIV : livre ; PR : presse ; ART : arts visuels ; ARCHI : architecture ; PUB : agences de publicité.

\section{2 - Estimation de la production des branches de la culture}

En 2013, les branches culturelles (audiovisuel, spectacle vivant, livre, presse, agences de publicité, architecture, arts visuels, patrimoine, enseignement culturel) totalisent une production de 88 milliards d'euros. Cette production se divise en deux parties : la production marchande et la production non marchande (tableau 3). 
La production marchande culturelle (72 milliards d'euros en 2013) correspond à la production de biens et services culturels destinée à être vendue sur le marché à un prix économiquement significatif, c'est-à-dire un prix couvrant plus de $50 \%$ des coûts de production, par convention de la comptabilité nationale. Cette production marchande inclut la production immobilisée constituant un actif générateur de recettes ultérieures, par exemple les films ou des programmes de télévision réalisés dans l'année pour une diffusion ultérieure (de l'ordre de 4 à 5 milliards d'euros).

Les niveaux à deux chiffres de la NAF (« division ») sont les niveaux les plus fins disponibles pour lesquels les données comptables (valeur ajoutée, production) sont diffusées par la comptabilité nationale à I'Insee. II est donc nécessaire, pour chacun des niveaux comportant au moins une activité culturelle, d'estimer la part culturelle et la part non culturelle pour parvenir à estimer la production de chacune des sous-classes de la NAF, niveau à 5 caractères (voir tableau des nomenclatures ci-dessus).

Pour ce faire, on part de la production marchande diffusée par la comptabilité nationale au niveau de la division (codes à 2 chiffres) et on calcule la production marchande au niveau de la sous-classe (codes à 5 caractères) en lui appliquant un coefficient calculé à partir des enquêtes sectorielles annuelles (ESA) de I'Insee. Ces enquêtes donnent en effet la décomposition du chiffre d'affaires des entreprises marchandes, décomposition détaillée par produits vendus, à un niveau très fin. Elles permettent donc d'avoir la répartition d'une branche identifiée par une division (2 chiffres) en chacune des sous-classes (5 caractères) retenues pour définir le champ de la culture. Cette clé de répartition est ensuite appliquée à la production au sens de la comptabilité nationale diffusée par division (2 chiffres) et qui diffère un peu de la somme des productions enquêtées par I'ESA, en raison de traitements spécifiques opérés par la comptabilité nationale. Les premiers résultats de l'ESA ont été publiés fin 2012 par l'Insee pour l'exercice comptable 2010, puis fin 2013 pour l'exercice 2011. On pourra poursuivre ces estimations chaque année.

La production non marchande culturelle (16 milliards d'euros en 2013) correspond quant à elle à des biens et services culturels proposés aux ménages à un prix non économiquement significatif, car bénéficiant de l'apport de dépenses publiques: partie du budget venant de l'État ou des collectivités territoriales, subventions versées à des associations, aides versées par les sociétés civiles. La production non marchande est par convention évaluée à son coût de production, qui regroupe majoritairement trois types de dépenses : la rémunération des salariés, la consommation intermédiaire et les dépenses d'investissement.

Alors que la production marchande est exclusivement produite par les entreprises, la production non marchande provient des administrations, des établissements publics ou encore des associations. Pour estimer la production non marchande des divisions 90-91 (création artistique et patrimoine), on part du total de la production non marchande donnée par l'Insee (total 90-91). Afin de mieux situer les branches culturelles que ne le faisait la comptabilité nationale avant la révision de 2014, la méthode élaborée par le DEPS en 2013 a réparti ce total en trois domaines (spectacle vivant, arts plastiques, patrimoine) à l'aide de plusieurs sources du ministère de la Culture (enquêtes sur les dépenses culturelles des collectivités territoriales, budget des établissements publics culturels notamment) permettant de répartir la dépense publique culturelle (rémunérations, investissement). La révision des comptes nationaux par l'Insee en 2014 a ensuite permis de rapprocher les chiffres de l'Insee de ceux estimés par le DEPS.

Pour l'enseignement culturel, on établit la production non marchande comme la somme de la dépense des centres de formation artistique (conservatoires régionaux, etc.), donnés par les comptes de l'Éducation élaborés par le ministère de l'Éducation nationale et des dépenses du ministère de la Culture et de la Communication pour les 
établissements d'enseignement supérieur Culture dont la tutelle ne dépend pas de l'Éducation nationale.

En 2013, environ $18 \%$ de la production culturelle est non marchande, soit davantage que la moyenne de l'ensemble de l'économie (12\%), mais beaucoup moins que dans d'autres branches économiques telles que l'action sociale et la santé (45\% de production non marchande) ou encore l'enseignement (82\%). L'activité non marchande culturelle est concentrée dans trois domaines: le patrimoine ( $96 \%$ de la production y est non marchande), l'enseignement culturel (86\%), le spectacle vivant (56\%). Les arts visuels (photographie, design, activités artistiques) comportent aussi une partie non marchande, mais marginale.

De 1995 à 2003, la part de la culture dans l'ensemble de l'économie a augmenté pour les deux composantes de la production, marchande et non marchande (graphique A).

\section{Tableau 3 - Répartition de la production et de la valeur ajoutée des branches} culturelles, en 2013

En milliards d'euros courants

\begin{tabular}{|c|c|c|c|c|c|c|c|c|}
\hline & \multicolumn{6}{|c|}{ Production } & \multirow{2}{*}{\multicolumn{2}{|c|}{$\begin{array}{c}\text { Valeur ajoutée } \\
\text { Totale }\end{array}$}} \\
\hline & \multicolumn{2}{|c|}{ Marchande } & \multicolumn{2}{|c|}{ Non marchande } & \multicolumn{2}{|c|}{ Totale } & & \\
\hline & Valeur & $\%$ & Valeur & $\%$ & Valeur & $\%$ & Valeur & $\%$ \\
\hline \multicolumn{9}{|l|}{ Répartition par domaine culturel } \\
\hline $\begin{array}{l}\text { Audiovisuel (radio, cinéma, } \\
\text { télévision, vidéo, disque) }\end{array}$ & 28,4 & 39,4 & & & 28,4 & 32,4 & 12,5 & 28,1 \\
\hline Livre, presse & 18,5 & 25,6 & & & 18,5 & 21,0 & 8,3 & 18,7 \\
\hline Spectacle vivant & 5,3 & 7,3 & 6,8 & 42,6 & 12,0 & 13,6 & 7,1 & 16,1 \\
\hline Publicité (agences de publicité) & 9,2 & 12,8 & & & 9,2 & 10,5 & 4,9 & 11,2 \\
\hline Patrimoine & 0,3 & 0,4 & 6,5 & 41,3 & 6,8 & 7,7 & 4,0 & 9,1 \\
\hline Architecture & 5,5 & 7,6 & & & 5,5 & 6,2 & 3,1 & 6,9 \\
\hline $\begin{array}{l}\text { Arts visuels (arts plastiques, } \\
\text { design photographie) }\end{array}$ & 4.6 & 6,3 & 0,6 & 4,1 & 52 & 59 & 26 & 58 \\
\hline Enseignement culturel & 0,3 & 0,5 & 1,9 & 12,1 & 2,2 & 2,5 & 1,8 & 4,1 \\
\hline Total Culture & 72,1 & 100,0 & 15,8 & 100,0 & 87,9 & 100,0 & 44,3 & 100,0 \\
\hline
\end{tabular}

Source : Insee, comptes nationaux - base 2010/DEPS, Ministère de la Culture et de la Communication, 2014

\section{Graphique A - Part des branches culturelles dans la production de l'ensemble de l'économie en valeur, 1995-2013}

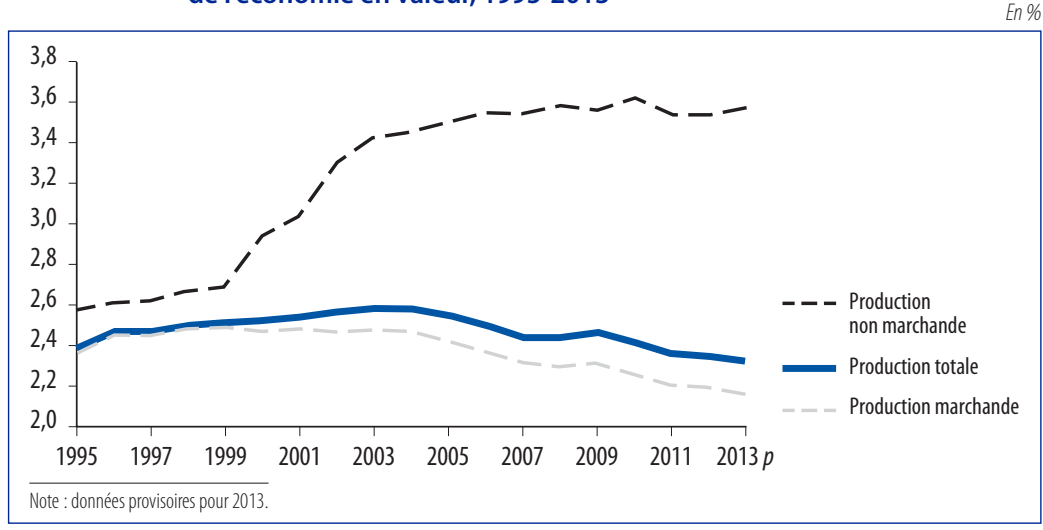

Source: Insee, comptes nationaux - base 2010/DEPS, Ministère de la Culture et de la Communication, 2014 
À partir de 2003 en revanche, la part des branches culturelles marchandes a reculé. La part culturelle de la production non marchande n'a cependant pas suivi la même évolution : continuant à augmenter entre 2003 et 2008 (ce qui a permis de limiter le recul du poids économique de la culture sur cette période), elle s'est ensuite maintenue à environ 3,6\% de l'ensemble de la production non marchande en moyenne sur 2008-2013.

\section{3 - Estimation de la valeur ajoutée des branches culturelles}

À cette production culturelle totale de 88 milliards d'euros correspond une valeur ajoutée des branches culturelles de 44 milliards d'euros en 2013 (tableau 3). Cette valeur ajoutée correspond à la production totale culturelle diminuée des consommations intermédiaires, c'est-à-dire de l'ensemble des produits ou services transformés ou consommés au cours du processus de production (matières premières, électricité par exemple). Mais les données de consommations intermédiaires manquent au niveau fin de la nomenclature.

Pour calculer la valeur ajoutée, on utilise le ratio valeur ajoutée (VA)/production, issu là encore des enquêtes structurelles annuelles (ESA) de I'Insee auprès des entreprises marchandes. Les valeurs ajoutées ainsi estimées par sous-classe (tous secteurs, y compris non culturels) sont ensuite sommées et calées au niveau de chaque division sur celles données par la comptabilité nationale (cette VA diffère en effet de celle issue de I'ESA à cause des traitements propres à la comptabilité nationale). La somme de ces valeurs ajoutées prises comme référence dans la comptabilité nationale ne donne pas tout à fait le PIB car il s'agit des valeurs ajoutées dites « aux prix de base », c'est-à-dire hors impôts et subventions sur les produits, qui ne sont pas diffusés par branche.

Pour les domaines partiellement non marchands (spectacle vivant, patrimoine, enseignement culturel), le ratio VA/production n'est pas fourni par l'ESA et on utilise, faute de mieux, le rapport VA/production donné au niveau de la division (2 chiffres) par la comptabilité nationale.

On estime ainsi une valeur ajoutée pour chacun des neuf domaines culturels, dont la somme donne la valeur ajoutée des branches culturelles pour 2011.

Cette méthode a le triple avantage d'être relativement simple à mettre en œuvre, d'être cohérente avec les données publiées à un niveau plus agrégé par la comptabilité nationale et d'être stable dans le temps. En revanche, elle est soumise aux règles propres à la comptabilité nationale, notamment en ce qui concerne le partage entre marchand et non marchand et elle ne permet pas de prendre en compte certaines spécificités de la culture. On ne peut donc pas lui préférer, avec les données dont on dispose, un partage entre les entreprises subventionnées et non subventionnées, ou moduler le critère des $50 \%$ des coûts de production pour distinguer le secteur marchand du secteur non marchand.

\section{4 - Estimation des deux années les plus récentes et rétropolation des séries chronologiques}

L'enquête structurelle annuelle (ESA) nous permet d'estimer la valeur ajoutée pour l'année couverte par cette enquête, la plus récente étant l'exercice 2011 (en 2014). Cette estimation se fait en mobilisant deux ratios: les décompositions des chiffres d'affaires des divisions en sous-classes détaillées, et le rapport entre valeur ajoutée et production pour chaque sous-classe.

Pour estimer le poids économique de la production marchande en 1995-2010 et 2012-2013, on fait évoluer ces coefficients à partir des évolutions annuelles de chiffre d'affaires (indices mensuels élaborés par I'Insee à partir des déclarations de TVA) pour chacune des sous-classes d'une division. Les données obtenues sont ensuite multipliées par un coefficient de redressement afin d'obtenir comme total la production marchande donnée par la comptabilité nationale au niveau de chaque division. 
Pour la production non marchande des autres domaines, on actualise le partage entre spectacle vivant/arts plastiques/patrimoine en 1996, 2002, 2006 et 2010 à partir des sources précédemment évoquées (enquêtes sur les dépenses culturelles des collectivités territoriales, sources ministérielles sur le budget des écoles supérieures Culture, comptes de l'Éducation, etc.) et on fait évoluer ce partage sur les années manquantes. Le total de la production non marchande des branches 90-91 est toujours donné par la comptabilité nationale. Pour l'enseignement culturel non marchand, on estime directement chacune des deux composantes (centres de formation artistique et enseignement supérieur) à partir des données annuelles des sources déjà mentionnées.

On calcule ainsi une production marchande et non marchande par domaine et pour chaque année. Pour calculer la valeur ajoutée en euros courants (en « valeur »), on procède comme pour le calcul sur 2011.

\section{5 - Estimation de la valeur ajoutée en volume}

Pour estimer la valeur ajoutée des branches culturelles en euros constants (en volume), on divise la valeur ajoutée estimée en valeur au niveau le plus fin de la nomenclature d'activités, par un indice des prix de la valeur ajoutée. Les indices des prix utilisés proviennent de deux sources: d'une part, les indices des prix de la valeur ajoutée par branche disponibles dans les comptes nationaux (au niveau division de la nomenclature, à 2 chiffres), d'autre part, pour les agences de publicité et les activités des divisions 58 et 59 (édition et une partie de l'audiovisuel), les indices des prix à la consommation des ménages du produit culturel se rapprochant le plus du poste considéré (par exemple, l'indice des prix à la consommation des journaux pour la branche $58.13 Z$ - Édition de journaux). En effet, pour ces branches, il apparaît indispensable de scinder l'évolution des prix en sous-activités détaillées pour mieux considérer les comportements de chaque branche (par exemple, hausse des prix des billets de cinéma, baisse des prix des DVD et des disques sur la période considérée; pour la division 73, évolutions très différentes des prix des activités créatives des agences publicitaires et de ceux des autres branches non culturelles comme les études de marché). Une voie d'amélioration de cette étape pourrait être d'utiliser les indices de prix de production des services, indices trimestriels diffusés par l'Insee depuis quelques années pour certains secteurs.

Enfin, la valeur ajoutée en volume ainsi obtenue est multipliée par un coefficient de redressement qui permet de retrouver, par sommation, la valeur ajoutée en volume publiée au niveau division par les comptes nationaux.

L'indice des prix de la valeur ajoutée des branches culturelles est alors obtenu en divisant la valeur ajoutée des branches culturelles en valeur (à prix courants) par celle en volume (à prix constants).

\section{6 - Révision des données de 2011}

Les données présentées dans cet article sont issues d'une méthode d'estimation de la valeur ajoutée mise au point en 2013 (Jauneau, 2013). Les données publiées par le ministère à cette occasion ont été toutefois révisées ici pour deux raisons.

D'une part, le périmètre du champ statistique de la culture a été très légèrement modifié, par l'ajout de cinq codes pour couvrir la totalité du champ totalement culturel et partiellement culturel défini par Eurostat. Ces inclusions ont pour effet d'augmenter de 0,15 point la part de la culture dans l'économie (graphique B). Cela révise à la hausse les poids relatifs dans la valeur ajoutée culturelle de l'audiovisuel (ajout de 47.63Z, 77.22Z) et, surtout, du livre et de la presse (ajout de 47.61Z, $47.62 Z$ et 74.30Z) au détriment des six autres grands domaines culturels (graphique C).

D'autre part, les concepts de la comptabilité nationale sur lesquels s'appuie cette méthode ont été révisés en mai 2014 par l'Insee (changement de base). Entre autres, les 
dépenses de recherche et développement sont désormais incluses dans le PIB et non plus comptées comme consommations intermédiaires. Cela a pour conséquence d'augmenter la valeur ajoutée dans les branches où ces dépenses sont fortes. Comme ce n'est en général pas le cas des branches culturelles marchandes, cela a eu pour effet de réviser à la baisse la part de la culture dans la valeur ajoutée de l'ensemble de l'économie (graphique B). Par branche détaillée, l'impact le plus notable de ce changement de base concerne l'audiovisuel, dont la valeur ajoutée est relevée, et le patrimoine, le spectacle vivant et l'architecture, qui sont quant à eux diminués (graphique C).

Les données précédemment publiées sur la période 1995-2011 ont été modifiées en conséquence. Les résultats présentés ici annulent donc et remplacent les données publiées par le ministère jusqu'à présent.

\section{Graphique B - Part des branches culturelles dans la valeur ajoutée totale,} 1995-2011

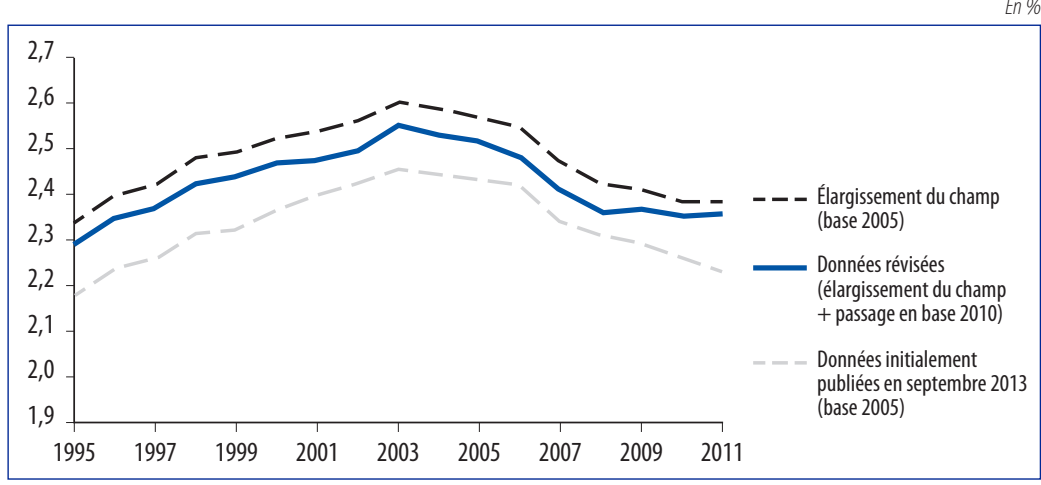

Source : Insee, comptes nationaux - base 2005 et 2010/DEPS, Ministère de la Culture et de la Communication, 2014

\section{Graphique C - Répartition de la valeur ajoutée culturelle par domaine en 2011 selon la méthodologie de calcul}

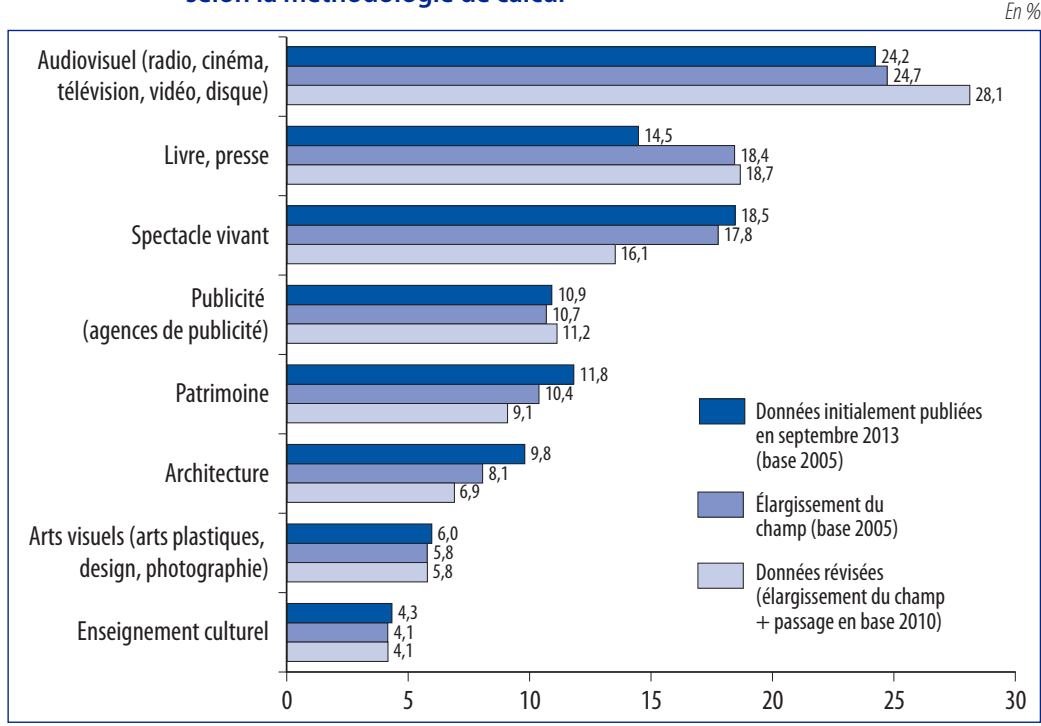

Source: Insee, comptes nationaux - bases 2005 et 2010/DEPS, Ministère de la Culture et de la Communication, 2014 


\section{Éléments de bibliographie et données en ligne}

Yves Jauneau, le Poids économique direct de la culture, Paris, Ministère de la Culture et de la Communication, DEPS, coll. «Culture chiffres», 2013-3, septembre 2013.

—, "La culture: quel poids dans le PIB ? », Cahiers français, n 382, août 2014, La Documentation française.

Valérie Deroln, Conceptualisation statistique du champ de la culture, Paris, Ministère de la Culture et de la Communication, DEPS, coll. « Culture méthodes », 2011-3, décembre 2011

Chiffres clés 2014, statistiques de la culture, Paris, Ministère de la Culture et de la Communication, diffusion La Documentation française, 2014.

Olivier Donnat, les Pratiques culturelles des Français à l'ère numérique. Éléments de synthèse 1997-2008, Paris, Ministère de la Culture et de la Communication, DEPS, coll. «Culture études », 2009-5, octobre 2009.

—, les Pratiques culturelles des Français à l'ère numérique, Paris, Ministère de la Culture et de la Communication/La Découverte, 2009 - www.pratiquesculturelles.culture.gouv.fr

«Les services marchands en 2013 - La croissance se réduit de nouveau », Insee Première, no 1507, juillet 2014.

"Les services marchands en 2013 - Rapport sur les comptes », Insee, Document de travail, E2014/06, juillet 2014.

Mélanie VANDERSCHELDEN, «La place du secteur associatif et de l'action sociale dans l'économie », Insee Première, $\mathrm{n}^{\circ}$ 1356, juin 2011.

Satellite Account on Culture in Spain. Advance of 2000-2009 results - http://www.mcu.es/ estadisticas/docs/CSCE/advance_results_csce-2010.pdf

"ESSnet Culture, Final report" (Eurostat grant agreement $n^{\circ} 10401.2008 .002-2009.352$ ), octobre 2012 - http://ec.europa.eu/culture/news/20121026-ess-net_en.htm

\section{Données et documents méthodologiques sur la comptabilité nationale}

Données détaillées et répartition de la valeur ajoutée par branche : http://www.insee.fr/fr/themes/theme.asp?theme=16\&sous_theme $=5.2$

Données détaillées sur la consommation des ménages : http://www.insee.fr/fr/themes/theme.asp?theme $=16 \&$ sous_theme $=2.3$

Données détaillées sur la dépense des administrations publiques par fonction : http://www.insee.fr/fr/themes/theme.asp?theme=16\&sous_theme $=3.3$

Notes méthodologiques sur les concepts et les méthodes d'estimation : http://www.insee.fr/fr/themes/comptes-nationaux/default.asp?page=base_2005/ methodologie/methodologie.htm 


\section{Abstract}

\section{The Direct Economic Impact of Culture in 2013}

In 2013, the direct economic impact of culture, i.e. the total value-added of all areas of culture, amounted to some 44 billion euros. This does not take into account any indirect economic knock-on effects or those generated by culture, such as tourism for example.

Thus calculated, culture accounts for 2.3\% of the economy as a whole, down slightly on 2012. This relative drop in 2013 was impacted by slower business activity in the more competitive sectors of architecture, advertising and audiovisual, as well as in the areas of press and book publishing. On the other hand, rising prices within the non-commercial sectors (e.g. live entertainment, cultural heritage) have helped boost their share of the cultural market.

Of those sectors most affected by the 2013 downturn, the audiovisual and advertising agency sector saw renewed growth in their turnover at the start of 2014, in contrast to the architecture and photographic sectors. Moreover, further increases in production costs for magazine and book publishing businesses have also been seen.

\section{À lire aussi}

\section{Chiffres Clés \\ Statistiques de la Culture 2014}

ISBN : 978-2-11-128154-7

144 p., $12 €$

En version numérique sur www.cairn.info

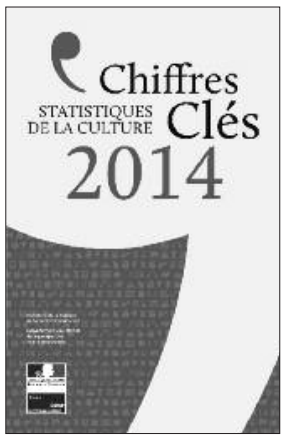

Décliner la culture en chiffres permet de prendre la mesure de la richesse foisonnante de la création, de l'offre artistique et de la diversité des pratiques artistiques et culturelles en France.

62 millions de visiteurs dans les 1200 musées de France, 2,8 millions de visiteurs dans les 23 fonds régionaux d'art contemporain et les 49 centres d'art contemporain. 14000 monuments classés au titre des monuments historiques, un millier de chantiers de fouilles archéologiques en 2012, ou encore plus de 2 millions de documents communiqués dans les services d'archives communaux, départementaux, régionaux et nationaux.

Plus de 1000 représentations lyriques qui attirent plus d'1,4 million de spectateurs par saison. Cinq théâtres nationaux, 70 scènes nationales, 17 zéniths, 39 centres dramatiques nationaux, plus d'une centaine de scènes conventionnées et plusieurs centaines de scènes et lieux de diffusion du spectacle privés... et des milliers de festivals chaque année en France.

Plus de 2000 cinémas, près de 16000 lieux de lecture publique et 500 conservatoires de musique et de danse où enfants et adultes peuvent se former à la musique, à la danse et au théâtre.

La France est riche d'une offre culturelle multiple et variée.

Chiffres clés 2014 en propose une approche objective et constitue ainsi un outil essentiel à la connaissance du champ culturel.

Directeur de la publication : Xavier Niel

Responsable de la publication : Edwige Millery

\section{Retrouvez l'ensemble des publications du DEPS sur : http://www.culturecommunication.gouv.fr/Etudes-et-statistiques et sur http://www.cairn.info}

Le DEPS n'assurant pas de diffusion physique de ses collections de synthèse, nous vous proposons de vous informer régulièrement des parutions par message électronique.

Pour ce faire, merci de bien vouloir nous communiquer votre courriel à l'adresse contact.deps@culture.gouv.fr 


\section{À lire aussi}

\section{2011-3}

\section{Conceptualisation statistique du champ de la culture}

Valérie Deroin

Décembre 2011, $12 p$.

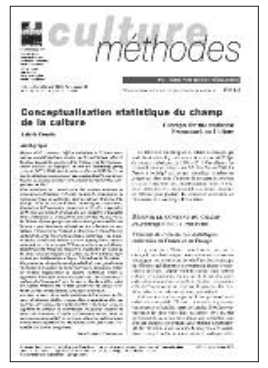

La définition du champ statistique de la culture a fait l'objet de travaux européens de 2009 à 2011, après que les nomenclatures nationales (nomenclature d'activités françaises, NAF Rév. 2) et européenne (nomenclature statistique des activités économiques dans la Communauté européenne, nace Rév. 2) ont été rénovées en 2008. Sous l'égide d'Eurostat, l'0ffice statistique de l'Union européenne, un groupe de travail européen (Task Force 1) a conçu la structure du nouveau cadre statistique européen constitué d'une trentaine d'activités culturelles, dans un souci d'harmonisation des outils méthodologiques et pour garantir une meilleure comparabilité des résultats publiés. Le cadre européen s'insère dans le cadre international défini par l'Unesco pour les statistiques culturelles et croise dix domaines culturels - patrimoine culturel, archives, bibliothèques, livre et presse, arts plastiques, audiovisuel et multimédia, architecture, création publicitaire, artisanat d'art - avec six fonctions économiques : création, production et édition, diffusion et commercialisation, conservation, formation, administration et management culturels. La publication revient sur les différentes nomenclatures existantes en France, en Europe et à l'échelon international et précise leur principe d'emboîtement. Publiée conjointement dans la collection " Culture études » du DEPS, Approche statistique européenne de la culture est la synthèse des travaux du réseau européen de statistique ESSnet-Culture et vient compléter utilement le présent document méthodologique.

\section{CE-2011-8}

\section{Approche statistique européenne de la culture} Synthèse des travaux européens ESSnet-Culture, 2009-2011

Valérie Deroin

Décembre 2011, 28 p.

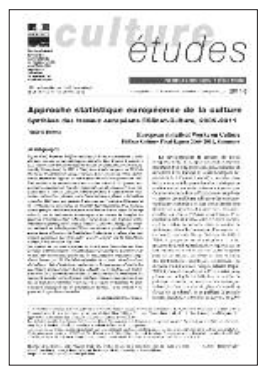

Sous l'égide d'Eurostat, I'Office statistique de l'Union européenne, le réseau du système statistique européen sur la culture (ESSnet-Culture) a dirigé, de 2009 à 2011, quatre groupes de travail consacrés à la définition du cadre statistique de référence, au financement de la culture et aux dépenses culturelles, à la mesure des secteurs culturels et de l'emploi, et enfin aux pratiques culturelles et à leurs aspects sociaux. La définition de la culture, la prise en compte de ses différentes dimensions, la question de la mesure des activités culturelles ont été des questions préalables à l'exercice de mesure et de comparaison statistiques. ESSnet formule plusieurs recommandations méthodologiques pour garantir une meilleure comparabilité des statistiques culturelles entre États membres.

Publié conjointement dans la collection " Culture méthodes », Conceptualisation statistique du champ de la culture revient sur les différentes nomenclatures statistiques existantes en France, en Europe et à l'échelon international, en précise les principes d'emboîtement, et vient compléter utilement la présente synthèse des travaux européens. 


\section{À paraître}

\section{CC2014-6}

\section{Vingt ans d'évolution de l'emploi dans les professions culturelles (1991-2011)}

Marie Gouyon, Frédérique Patureau

Octobre 2014, 24 p.

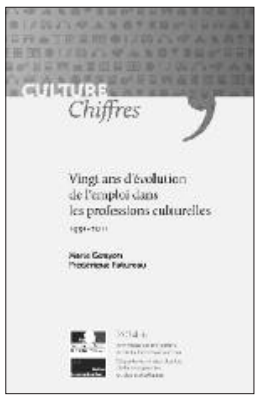

Professions des spectacles et des arts visuels, métiers d'art, journalistes, écrivains, conservateurs, documentalistes, architectes, professeurs d'art, etc. : les professions culturelles constituent un ensemble particulièrement hétérogène du point de vue de leurs effectifs, mais aussi de l'encadrement juridique dont elles font l'objet, des statuts d'emploi dans lesquels elles s'exercent, ou encore des compétences et savoir-faire qu'elles mobilisent. Elles ont cependant pour point commun de s'être considérablement développées au cours des vingt dernières années.

Au début des années 1990, 381000 personnes déclaraient exercer à titre principal une profession culturelle. Vingt ans plus tard, elles sont 573000 , soit $50 \%$ de plus. Dans le même temps, l'ensemble de la population active en emploi a augmenté de façon nettement plus modérée (+ $16 \%)$. La part des professions culturelles dans l'ensemble des actifs en emploi s'est donc accrue sensiblement et atteint 2,2 \% en 2011

L'emploi culturel est majoritairement masculin mais s'ouvre lentement aux femmes, tandis que la concentration historique des emplois en Île-de-France tend à s'atténuer. Plus diplômés que l'ensemble des actifs, les professionnels de la culture exercent plus souvent leur activité sous statut indépendant, tandis qu'au sein du salariat, la fragmentation de l'emploi se confirme : temps partiels et contrats courts continuent à se développer.

\section{CC-2014-7}

\section{Les industries culturelles en France et en Europe : points de repère et de comparaison}

\section{Roxane Laurent}

Octobre 2014, 20 p.

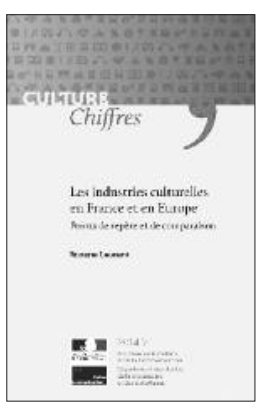

En 2011, le poids des industries culturelles (audiovisuel et multimédia, activités liées au livre et à la presse, services des agences de publicité) dans l'ensemble de l'économie marchande est de 2,6\% en France, I'un des plus élevés d'Europe. Supérieur à celui de l'Allemagne $(2,1 \%)$, il reste toutefois inférieur à celui des industries culturelles au Royaume-Uni $(3,2 \%)$.

En France, l'audiovisuel et le multimédia contribuent majoritairement à l'activité des industries culturelles, à la différence de l'Allemagne et du Royaume-Uni où le livre et la presse prédominent. Certaines activités françaises comme le jeu vidéo, la production et la post-production de films cinématographiques, de vidéos et de programmes télévisés contribuent pour plus d'un tiers de l'ensemble de l'activité au niveau européen. Les agences de presse sont en revanche principalement anglaises, tandis que l'Allemagne occupe une place très importante dans les secteurs du disque, de la radio et des journaux.

Comme dans tous les secteurs de l'économie marchande, la rentabilité des entreprises culturelles françaises, mesurée ici par leur taux de marge, est plus faible que celle de l'ensemble des entreprises européennes, du fait de coûts pesant sur les facteurs de production. Les secteurs de la presse et les agences de publicité présentent des taux de marge particulièrement faibles. Selon cet indicateur, les jeux vidéo et la production de films sont les secteurs culturels français les plus rentables, tandis qu'en Allemagne et au Royaume-Uni, ce sont plutôt les activités liées à la presse, et en Italie celles liées à la musique. 
